\title{
On possibilities for development of human adaptive resources in arctic conditions
}

\author{
V.V.Semikin*, R.A.Kochkin, O. Yu.Mezhina, and T.L. Popova \\ Sector of Social and Psychological Research of the State Public Institution "Reseaech Center for the \\ Study of the Arctic" Nadym, Yamal-Nenets Autonomous District, Russia.
}

\begin{abstract}
This article presents the results of an experimental study aimed to investigate perspectives of the intentional development of adaptive resources of the human organism in the context of the harsh Arctic environmental conditions. The effectiveness of the author's comprehensive psychophysical training program designed to develop mechanisms of human psycho-physiological and mental self-regulation has been tested in a formative experiment. The study was conducted on a sample of 18 clinically healthy female patients with an average age of $40 \pm 5.6$ years and the northern experience of $18.3 \pm 10.6$ years. The results showed a significant change in several measurements indicating the improvement in some important characteristics of the functional state of subjects as a result of the psychophysical training. These changes suggest an increase in the adaptive potential of the subjects due to the formation experiment.
\end{abstract}

\section{Introduction}

One of the markers of human well-being is health. According to the World Health Organization (WHO) definition, health is "a state of complete physical, mental and social well-being and not merely the absence of disease or infirmity" [1]. Health constitutes the foundation and provides opportunities for the adaptation of the human body to various climatic or psychological conditions, personality growth, and self-realization.

Currently, significant changes in environmental, technological, demographic, socioeconomic, and socio-cultural factors of modern Russian society have exacerbated the problem of maintaining health. Those changes in living conditions directly or indirectly endanger human health, personal well-being and quality of life [2].

The urgency of the problem increases in the light of state objectives put forward in recent years, including the President's strategic vision of increasing life expectancy and longevity and promoting healthy and active ageing [3]. The health problem is of particular importance for the inhabitants of the Far North. It is no coincidence that one of the challenges addressed in the Decree of the President of the RF entitled "The strategy for the development of the Arctic zone of the Russian Federation and provision of national security through 2035 " is the development of technologies aimed to preserve health and increase the life expectancy of the population in Arctic zones [4].

Life and activities in the Arctic are associated with a heavy burden on the human body and psyche, where harsh climatic, geographical, and geophysical conditions affect the population, especially newcomers, as factors of an extreme nature. The stability of the human body in these conditions depends largely on its adaptive abilities (resources). The

\footnotetext{
${ }^{*}$ Corresponding author: semikin v@mail.ru
} 
shortage in adaptive resources can lead to body functional systems disorders, and eventually, provoke diseases [5].

It is well known that the adaptation process in the human body is determined by functioning of its regulatory mechanisms or the hierarchy of the functional systems.

Thus, the level of a person's adaptive resources depends on the degree of formation of her/his multi-level self-regulation systems. Resources for health, resistance against adverse factors, adaptive potential, and vitality are harbored in regulatory properties of the body $[6,7,8]$.

Research in this area has been carrying out in the Arctic zone of the RF, including the Yamal-Nenets autonomous district, for many years. On the district territory, the YaNAO State Public Institution 'Research Centre for Arctic Studies' undertakes multidisciplinary scientific research on the YaNAO population health for the period from 2010 to 2020, and specifically, explores the process of adapting to the harsh climatic and geographic conditions of the arctic region, as well as social-psychological adaptation process and the satisfaction with the living conditions [9].

As the results of these studies show, the majority of the most productive segment of the Yamal population, aged 30-50, assess the state of their health negatively. The reasons they report as contributing to this situation are very diverse: harsh climatic conditions, the special nature of the northern photoperiodicity, specific features and complexity of the work under these conditions, the social and domestic stress, and the prolonged absence of complete rest [10].

As a continuation of these studies, in 2020, the sector of social and psychological research of Yamal-Nenets Research Center for the Arctic Study has designed and conducted an experiment aimed to develop and test a program for the development of the human adaptive potential in the northern climate conditions, as a part of a comprehensive research project "Development of conceptual approaches and scientific and methodological foundations for protecting the health of residents of the Arctic region."

The following hypothesis has been proposed: a person can increase her/his adaptive resources by developing the psycho-physiological self-regulation potential through purposeful psychophysical training..

\section{Research Design and Methods}

\subsection{The program of formative intervention}

Starting from the proposed hypothesis, the logic and design of the present field study have been built, and a program of the formative intervention has been developed as a sequence of six interconnected modules of psychophysical training with increasing complexity. Each complex is designed for a week of daily exercises lasting 1.5 hours.

The program was based on the author's concept of purposeful self-regulation of the functional state [11], as well as the principle of subjects' active involvement in the selfdevelopment activities $[12,13]$. According to this principle, the subjects had been carrying out various self-guided developmental activities every day for a period of six weeks (42 training sessions) under the general supervision of a qualified coach, while 2 sessions a week were held in a group format under the direct supervision of the couch.

In the formulation of the program were used advances in integrative medicine [14], health psychology, and psycho-hygiene [15], as well as elements of development and health technologies offered by the body-oriented approach, cognitive-behavioral therapy, yoga therapy [16], and auto-training [17]. 
The program was designed to provide purposeful improvements in physiological, psycho-physiological, and mental self-regulatory mechanisms.

\subsection{Methods}

To evaluate the dynamic of psycho-physiological and mental parameters of the subjects' functional state during the formation experiment, three following standardized techniques were used [18]:

1. Differential rating scale to evaluate changes in the subjects' functional state using such subscales as "well-being", "activity", and "mood" (WAM).

2. Lüscher color test to evaluate the index of vegetative balance and the perceived responded wellness vs. unwellness (autogene norm $\pm \mathrm{SE}$ )

3. Technique of the sleep disorders (the quality of sleep) assessment using the Aleksandrovich questionnaire with 5 perceived responded symptoms: "insomnia, sleep disorders", "difficulties falling asleep", "nocturnal awakening", "frightening dreams, nightmares", "daytime sleepiness" [19].

Values at the WAM scales and the Luscher's test were measured on the onset and after the experiment termination, and additionally twice a week before and at the end of a training session. Sleep disorders were assessed only before and after the entire period of the experiment.

\subsection{Statistical analysis}

The data obtained were analyzed with the Statistica for Windows v.8.0 program (StatSoftInc., US). All values are expressed as means \pm SD, differences were evaluated using the Student's t-test, statistical significance was set at a $P$ value of less than .05 or $P$ value of less than .01 . The normality of distribution was analyzed using the Shapiro-Wilk test.

\subsection{Sampling method}

The sample of subjects was randomly selected. It included 18 clinically healthy women living in the city of Nadym, Yamal-Nenets Autonomous District. The average age of the subjects was $40 \pm 5.6$ years, with the northern experience of $18.3 \pm 10.6$ years. All subjects signed the informed consent, understood their tasks in the study, and were motivated to improve their adaptive potential.

\section{Results}

Table 1. The Autonomous balance index (mean \pm SD) changes under the influence of psychophysical training

\begin{tabular}{|l|c|c|}
\hline & $\begin{array}{l}\text { Before training } \\
\text { sessions }\end{array}$ & $\begin{array}{l}\text { At the end of training } \\
\text { sessions }\end{array}$ \\
\hline psychophysical training n. 1 & $1.28 \pm 0.36$ & $\mathbf{1 . 6 5} \pm \mathbf{0 . 7 2 *}$ \\
\hline psychophysical training n. 2 & $1.30 \pm 0.50$ & $1.11 \pm 0.41$ \\
\hline psychophysical training n. 3 & $1.31 \pm 0.28$ & $\mathbf{1 . 7 0} \pm \mathbf{0 . 3 7 * *}$ \\
\hline psychophysical training n. 4 & $1.65 \pm 0.58$ & $1.63 \pm 0.64$ \\
\hline psychophysical training n. 5 & $1.32 \pm 0.57$ & $1.37 \pm 0.48$ \\
\hline psychophysical training n. 6 & $1.30 \pm 0.39$ & $\mathbf{1 . 6 0} \pm \mathbf{0 . 3 3} *$ \\
\hline
\end{tabular}

Note: statistical significance expressed with the Student t-test, ${ }^{*} \mathrm{p}<.05, * * \mathrm{p}<.01$. 
This table presents the dynamic of the index of vegetative balance (IVB) values immediately at the end of training sessions. In three modules out of six, they were significantly increased, which indicates an increase in the ergotropic element of the autonomic self-regulation system within the vegetative balance range. A significant increase in the ergotropic element of the vegetative balance (0.92 to 1.9 points) demonstrated the ANS activity optimization as has been manifested in the increase in activity, readiness to energy expenditure, and performance efficiency of the subjects as the result of training exercises in these three training modules (training n.1, n.3, and n.6).

Significant changes in the index of vegetative balance were accompanied by significant improvements in the average scores of the psychological indicators "well-being" and "mood" as perceived, that is, at the level of conscious experiences (see Table 2), suggesting that there were systemic changes in the psycho-physiological organization of the subjects, namely, optimization of their functional state.

Table 2. Dynamics of average values of the WAM test $(M \pm S D)$ under the influence of the psychophysical training

\begin{tabular}{|l|l|l|l|r|l|}
\hline \multicolumn{3}{|l|}{ Before training sessions } & \multicolumn{3}{|c|}{ At the end of training sessions } \\
\hline Well-being & Activity & Mood & Well-being & Activity & Mood \\
\hline $5.17 \pm 0.82$ & $4.98 \pm 1.01$ & $5.67 \pm 0.86$ & $\mathbf{5 . 8 3} \pm \mathbf{0 . 7 4}$ & $4.57 \pm 1.27$ & $\mathbf{6 . 1 1} \pm \mathbf{0 . 5 3}$ \\
\hline
\end{tabular}

Note: statistical significance expressed with the Student t-test, ${ }^{*} \mathrm{p}<.05$.

Analysis of changes in the psycho-physiological and mental scales values at the end of the experiment (see Table 3) revealed a significant increase in the index of vegetative balance up to $1.5 \pm 0.41(\mathrm{p}<0.05)$, which corresponds to the optimal value level of the autonomous nervous system balance.

A simultaneous decrease in the average values of the SD from $16.0 \pm 3.11$ to $14.0 \pm$ $2.20(\mathrm{p}<0.05)$ indicates mental stress reduction and the increase in the feeling of "wellbeing" in subjects. The significant changes in the "well-being" and "activity" scores values (up to $5.9 \pm 0.38(\mathrm{p}<0.01$, and up to $5.3 \pm 0.32 \mathrm{p}<0.05)$ confirm the positive remodeling of the subjects' functional states. Values of the "mood" parameter remain within the average norm.

Table 3. Dynamics of mean values $(\mathrm{M} \pm \mathrm{SD})$ in subjects during the experiment

\begin{tabular}{|l|c|c|c|}
\hline \multirow{2}{*}{ Scales } & \multicolumn{3}{|c|}{ Psycho-physiological diagnostics } \\
\cline { 2 - 4 } & Baseline values & $\begin{array}{c}\text { At the midpoint of the } \\
\text { experiment }\end{array}$ & $\begin{array}{c}\text { At the end of the } \\
\text { experiment }\end{array}$ \\
\hline Well-being & $5.2 \pm 0.95$ & $5.4 \pm 0.74$ & $\mathbf{5 . 9} \pm \mathbf{0 . 3 8 * *}$ \\
\hline Activity & $4.8 \pm 0.92$ & $\begin{array}{c}\text { At the midpoint of the } \\
\text { experiment }\end{array}$ & $\begin{array}{c}\text { At the end of the } \\
\text { experiment }\end{array}$ \\
\hline Mood & $5.8 \pm 0.84$ & $5.7 \pm 0.54$ & $5.5 \pm 1.14$ \\
\hline $\begin{array}{l}\text { Autonomous } \\
\text { balance index }\end{array}$ & $1.3 \pm 0.49$ & $1.3 \pm 0.42 \mathrm{c}$ & $\mathbf{1 . 5} \pm \mathbf{0 . 4 1 *}$ \\
\hline $\begin{array}{l}\text { Total deviation } \\
\text { from the } \\
\text { autogene norm }\end{array}$ & $16.0 \pm 3.11$ & $16.2 \pm 3.04$ & $\mathbf{1 4 . 0 \pm 2 . 2 0 *}$ \\
\hline
\end{tabular}

Improvements in the "sleep quality" rates at the end of training sessions (see Table 4) further suggest that the factor "psycho-physical training" does optimize the functional state and contribute to the self-reported "well-being" of subjects.

Clear improvement tendencies can be seen in ratings in the Aleksandrovich technique: "insomnia, sleep disorders", "difficulty falling asleep", and " nocturnal awakening" at the end compared to the baseline values. Another two symptoms, "frightening dreams, 
nightmares" and "daytime drowsiness" demonstrated a 100\% relief (total recovery). Thus, the experiment resulted in sleep normalization in the majority of the subjects.

Table 4. Dynamics of mean values for sleep disorders in subjects during the experiment.

\begin{tabular}{|l|c|c|c|}
\hline \multirow{2}{*}{ Parameters } & \multicolumn{3}{|c|}{ Psychophysiological diagnostics } \\
\cline { 2 - 4 } & $\begin{array}{c}\text { Baseline } \\
\text { values } \\
\%\end{array}$ & $\begin{array}{c}\text { At the midpoint of } \\
\text { the experiment } \\
\%\end{array}$ & $\begin{array}{c}\text { At the end of } \\
\text { the experiment, } \\
\%\end{array}$ \\
\hline 1.Insomnia, sleep disorders & 38.8 & 27.7 & 16.6 \\
\hline 2.Difficulties falling asleep & 44.4 & 33.3 & 22.2 \\
\hline 3.Nocturnal awakening & 55.6 & 22.2 & 16.6 \\
\hline 4.Frightening dreams, nightmares & 11.1 & 0.0 & 0.0 \\
\hline $\begin{array}{l}\text { 5.Daytime sleepiness, insurmountable } \\
\text { drowsiness forcing to fall asleep, for some } \\
\text { moments at least, whatever the circumstances }\end{array}$ & 44.4 & 33.3 & 0.0 \\
\hline
\end{tabular}

\section{Conclusion}

The obtained results confirmed the hypothesis of the study, that is, it is possible to improve human adaptive resources in extreme climatic-geographical and geophysical conditions through special psychophysical training addressing the multilevel system of psychophysiological self-regulation of subjects. Significant changes in values of some psychophysiological and mental functional state parameters of the subjects support this conclusion.

\section{References}

1. Constitution of the World Health Organization, adopted in New York 22 July 1946

2. G.S. Nikiforov, Healthy personality (Rech, St.Petersburg, 2013)

3. Decree of the President of the RF of May 7, 2018 N 204 "On national goals and strategic objectives of the development of the Russian Federation for the period until 2024".

4. Decree of the President of the RFof March 5, 2020 N 164 "On the Fundamentals of State Policy of the Russian Federation in the Arctic for the Period up to 2035".

5. .M. Akimov, O. M. Barbakov, M.L. Belonozhko and others; Health preservation of participants in the development of the Arctic oil and gas region (TIU, Tyumen, 2019)

6. S.T. Posokhova, Psychology of an adapting personality: a subjective approach: Dis Doctor of Psychology (St. Petersburg, 2001).

7. A.V. Makhnach, A.I. Laktionova, In: Psychology of adaptation social environment: modern approaches, problems, prospects, 290-312 (IP RAN, Moscow, 2007)

8. E.A. Rylskaya, Siberian psychology. J.31, 6 (2008)

9. T.L. Popova, A.I. Popov, Scientific bulletin of the YNAO. 4 (93), 133-138 (2016).

10. T.L. Popova, E.V.Agbalyan, E.V. Shinkaruk, Scientific Bulletin of the YANAO, 3(104), 46-51 (2019).

11. V.V. Semikin Purposeful self-regulation of a functional state in a continuous activity mode (Moscow 1986).

12. O.A. Konopkin, Questions of psychology, J. 2, 128-135 (2004) 
13. V.M. Bogdanova, E.L. Dotsenko, Self-regulation of personality: from defenses to creation (Mandr and $\mathrm{K}^{\mathrm{a}}$, Tyumen, 2010).

14. S.A. Partsernyak, Integrative medicine: from ideology to the methodology of health care (Normedizdat, St. Petersburg, 2007)

15. G.S. Nikiforov, Health psychology: Textbook for universities (St. Petersburg, Peter, 2006)

16. A. Frolov Yogotherapy: Hatha yoga as a method of rehabilitation (Orientalia, Moscow, 2016)

17. A.A. Alexandrov, Auto-training: Handbook (St.Petersburg, 2007)

18. L.F. Burlachuk, Dictionary-handbook on psychodiagnostics (Piter, St.Petersburg, 2003)

19. B.D. Karvasarsky Clinical psychology. Textbook. (Moscow, 2004) 